\title{
The Application of Peer Education Idea in Guiding Community Troublesome Youngsters
}

\author{
Zhanlu Xu \\ Qian Jiang College, Hangzhou Normal University, Hangzhou, 310012, China
}

Keywords: Peer education, Community, Troublesome youngsters

\begin{abstract}
Peer education in domestic and foreign student education has achieved good effect, especially in the students' mental health, adapting to the environment. Community troublesome youngsters as a special group, who treat the sermon of parents and teachers as " offensive ", their words and deeds do not accord with the mainstream values, they are susceptible to partners, and they have strong senses of self-esteem. In the face of such a group, the community do not set up special organizations and form a team of experts, so there are many problems in the education of youth in terms of. Under the guidance of experts, classifying the problems of the troublesome youngsters, with the leading of outstanding peers, it will make better effect than the sermon of parents and teachers, that is evidenced by the community in Hangzhou. Of course, we should comply with certain principles and pay attention to methods in the use of peer education idea to counsel community troublesome youngsters.
\end{abstract}

\section{Concept of Peer Education}

\section{Emergence of Peer Education}

The original meaning of peer education refers to that, due to the same background or because of some specific reason, people using the same language share information, concepts or behavior skills together, so as to realize the educational objective. In developed countries, it has been widely applied to prevent AIDS, STD and safe sex, which has produced quite good effects. [1]

In the year of 1969, Vriend from America published the first paper related to the field of peer psychological consultation. In 1984, America established the National Peer Helpers Association, which was renamed as the National Association of Peer Programs. [2] Nowadays, in many colleges and senior schools of America and Canada, there are peer counseling centers, which help them to solve all kinds of problems confronted in learning, life and psychology. ${ }^{[3]}$ WHO has already confirmed that it is an effective way to change people's behaviors, especially the teenagers' behaviors, and also one major measure to prevent HTV/AIDS on the global scale. On the $12^{\text {th }}$ International AIDS Conference in 1998, Australia and America introduced the researching experiencing of peer education in preventing AIDS. According to related data, a lot of high schools and universities abroad have opened the peer education. However, there are certain limits in the aspect of application object and scope, which are mainly applied to help teenagers at school.

\section{Development and Application of Peer Education in China}

Researches on peer education for teenagers in China start from middle and primary schools. In 2005, Xuzhou of Jiangsu province took the initiative to put forward "Students Growth Partnership" in education of primary schools. In China, the peer counseling has developed quite late. Most researches have been concentrated on the peer education of university students’ AIDS. For instance, Xu Gang developed the AIDS peer education in some medical university. [4] Currently, according to incomplete statistics, many domestic universities have already implemented the self-help growth mechanism of peer education, including Peking University, Zhejiang University, Ji'nan University, Central China Normal University, Sun Yat-Sen University, Nanjing Medical University, etc. Senior students guide and manage the new students, which has obtained certain effects. It is a beneficial attempt to make innovations of managing university students. 


\section{Current Situations of Community Education Troubled Juveniles}

\section{Scope of Community Troubled Juveniles}

In 2002, Shanghai was the first to put forward the concept of "Community Juvenile", which defined community juveniles as "aged 16-25, no fixed jobs or income, taking no further study". [5] The author considers that, community troubled juveniles have two scopes, in the broad and narrow sense. In the narrow sense, the community troubled juveniles refer to: aged around 15-20, in the psychological rebellious phase; during the progress of learning, life or stepping into the society, all their behaviors cannot be accepted by the mainstream values. In the broad sense, the community troubled juveniles also include those who have already violated the laws but served sentence out of prison, such as release on parole or imprisonment with a suspension of sentence. These juveniles belong to the scope of social rectification. In this paper, it discusses the community troubled juveniles in the narrow sense.

\section{Manifestation and Reason of Community Troubled Juveniles}

Manifestation and Hazard of Community Troubled Juveniles

During recent years, population of Chinese community troubled juveniles has been on the rise. Common manifestations of community troubled juveniles include: emotional problem(depression or anxiety), network addiction, violence self-injury or injury by others, abuse of psychoactive drug substance, psychological inversion, inferiority, suspicion, suicide, sex psychological trouble, maladaptive interpersonal relationship, etc. All these problems often lead juveniles to have several dangerous behaviors. A greater proportion of juvenile delinquency is resulted in because troubled juveniles are not persuaded or regulated in time.

Reasons Leading to the Phenomenon of Community Troubled Juveniles in China

Factor of Juveniles

Troubled juveniles are in adolescence, who are rebellious, having big emotional fluctuations, easy to be affected by the social groups, having low identification of the social circumstance. As a consequence, they are willful, who cannot control emotions or behaviors, but result in problems of fighting or network addiction, further to affect their learning life.

Factor of Family

In-harmony family: divorced parents, remarried parents, single parent family or parents often having quarrels; family without proper education: improper educational method, spoil, hit \& scold, unfettered kids; family without morality: parents do not behave well in the aspect of social morality, who affect the children, such as parents have violent characters, enjoy profit at other people's expense; family without talents: parents have low cultural backgrounds, who are incapable of educating children well. [6]

Factor of Education

At the present stage, educational modes of Chines schools at all levels are still dominated by big class group education, which cannot actually pay attention to the psychological or individual differences of juveniles; in the evaluation system of students, they merely judge the abilities of students by the scores of examinations, which have existed in schools at all levels; the derivation of teachers in the aspect of educational concept and method has also become one factor damaging the psychological health of juveniles.

\section{Problems of Community while Educating Troubled Juveniles}

Emergence of community troubled juveniles is ill-suited for the lack of governmental management organizations.

Community troubled juveniles is a special group among juveniles. For this special group, the nation and governments at all levels have already attached deserved importance to that. Such as the educational system, it has set up organizations as "China National Committee for the Well-being of The Youth" and “Juvenile Protection Office”. However, we must see that, "all these organizations are respectively spreading over all departments of the government, which enables the government to be lack of an unified coordination organization to manage the juvenile affairs. Thus the strength seems to be not enough more or less”. [7] 
Related organizational settings of community are not standard and there are insufficient staff. Although many places have cooperated with the Communist Youth League and set up Community Communist Youth League Working Committee, such organizations have focused on undertaking activities with the theme of youth and expanding the youth's abilities to participate in activities. However, for juveniles having all kinds of problems and needing help, there are no specific departments or professional community organizations.

\section{Application of Peer Education Concept to Counsel Community Troubled Juveniles}

\section{Psychological Characteristics of Juveniles}

Strengthened Independent Consciousness. As juveniles grow up, they will communicate with the society wider and wider. Their desire of independence has increasingly become strong. They have gradually begun to be alienated from the family, doubted about the parents' authority and even produced the rebellions. Therefore, when they have conflicts with parents, they often show the tendency of "getting rid of the family restraint".

Close partnership. Peers and partners are quite important social relationship of juveniles during the social interaction. After entering the adolescence, with broader scope of actions, juveniles have gradually turned their rely on family to the partners, so as to form intimate partnership. Their behaviors, hobbies and clothing affect each other.

\section{Concrete Application of Peer Education Concept in Counseling Community Troubled Juveniles}

Application of peer education concept should conform to the psychological characteristics of juveniles. Community troubled juveniles are in adolescence, who need more attention and guidance. Because they are in the rebellious phase, traditional preaches, especially control of teachers and parents, are "hard to be accepted", the leading effects of the peer will be better.

Communities should set up specific organizations and construct professional teams to offer platforms for the peer education.

Communities can set up Juvenile Affairs Management Center and organize one assisting team composed of professional guidance personnel. By cooperating with the surrounding high schools and universities, communities can offer posts for students to practice, and schools offer volunteers for communities. Especially, volunteers majored in psychology and social work should be promoted to join in assisting juveniles, so as to strengthen their abilities to apply professional theoretical knowledge to practice, exercise their consciousness of serving the society and lay a good foundation for university students to step into society.

Targeted at troubled juveniles of different types, different peer education methods should be adopted. In Researches on Problems and Countermeasures of Contemporary Juveniles, Gao Zhongjian systematically illustrates ten dominant problems of contemporary juveniles, including value problem, morality problem, culture problem, psychology problem, marriage problem, network problem, security problem, misconduct problem, illegal crime problem and development problem. ${ }^{[8]}$ Combined with the practice of community troubled juveniles, juveniles can be classified into:

Psychological troubled juveniles

First of all, weary of studying. It is the negative emotion of students in learning and the reactive mode to negatively treat the learning. Juveniles are in the golden period of learning. Learning activities in this period is the foundation for juveniles to step into the society. However, among community troubled juveniles, a larger proportion are students weary of studying. Therefore, under the guidance of teachers, students enjoying studying can study with those weary of studying together. Through the demonstration of peer learning behavior, they can set good examples for students weary of studying.

Secondly, rebellious. Juveniles have rebellious thoughts and behaviors, go against the normal rules, obey original intention of others and often do something unexpectedly. Juveniles in "rebellious period" often have obvious psychology of "anti-control" and "resistance" to educators. Juveniles have to suffer the rebellious period, but if their rebellious behaviors have already affected their learning and study, it is quite serious, which needs to be guided in time. 
Thirdly, the problem of interpersonal relationship. Juveniles are in adolescence, who cannot handle all kinds of problems maturely. They are quite sensitive and excited confronted by problems. Consequently, in the aspect of interpersonal relationship, professionals should make analysis and find out the roots of interpersonal relationship. If any problem happens between juvenile and parent or teacher, professional counselors can communicate with parents and schools, so as to gradually solve the interpersonal relationship of juveniles.

\section{Principles Followed by Peer Education Concept While Being Applied to Counseling Community Troubled Juveniles and Methods}

Principles should be followed by peer education concept while it is applied to counsel the community troubled juveniles

Application of peer education concept should stick to the coordination between the peer education and all education.

All community departments should attach enough importance to the education of troubled juveniles. Communities should establish professional functional departments to help juveniles, set up the panel of experts, classify troubled juveniles reflected by the communities, conduct peer education guidance according to concrete situations, communicate with schools and parents, thus educational method can be implemented smoothly.

Application of peer education concept should stick to integration of periodical education and objective education.

As the assistance of troubled juveniles, the supporting objective should be divided into several stages, so as to be gradually implemented as planned, step by step. During this progress, advantages of community troubled juveniles should be affirmed. By summarizing good experience and determining new starts, anticipated objectives can be gradually realized, so as to achieve the final purpose.

Application of Peer education concept should stick to the integration of oriented education and spontaneous education.

Educators should guide pee partners. Under the premise of respecting juveniles, they should make comprehensively scientific analysis on their interests, hobbies, wished and characters, be good at discovering their advantages, let them realize that individual behaviors should conform to principles, and let them understand right and wrong, and also moralities.

Integration of Consistent Demand and Diversified Method

To apply the peer education concept to the community troubled juveniles, it mainly aims at assisting the community in solving problems of juveniles. The peers need to combine with the individual differences of interests, abilities, temperaments and characters of troubled juveniles, and also mistakes they have made, select proper supporting contents and corresponding ways, patiently apply flexible and easy-to-be-accepted ways to educate them, further to open different locks with different keys.

Integration of Reasoning Education and Demonstrating Education

Although characteristics of the peer education lie in the behavior influence on the peers, words and deeds of partners have larger influence on the juveniles than those of parents and teachers. Therefore, reasoning education is an important method for troubled juveniles, who should be educated with reasons and led by actions. Peers should set good examples for them, touch and influence them unconsciously, thus juveniles can erect correct value of life, morality and values.

Integration of Collective Education and Individual Education

Currently, with the reform of social educational mode, juveniles have a lot of spare time to stay in communities, such as after class, after school, weekends, summer and winter vacations. Communities can take advantage of field, organize and motivate troubled juveniles to join in collective activities and public benefit activities together with their peers, thus they can produce sense of responsibility and achievement during the activities, further to rectify their misconducts. ${ }^{[10]}$ In collective activities, the first is the edification of good examples; the second is the positive spiritual influence. 


\section{Conclusion}

As the peer education method under the guidance of peer education concept, after the adaption and growth of university students, it has obtained many achievements. It plays the role of good example and has obvious influence on the educated groups. While being confronted by the special group of juveniles, it enables this group to learn from good examples, so as to ease the burden of parents and communities. It's worth the try. However, any method is not everything. Application of peer education should be recognized by communities and person in charge and be guided by instructors. Meanwhile, it must possess certain foundation of knowledge, so as to stand the test, guide the educated groups from the perspective of ideology and behavior. To realize better effects, it needs to consistently improve the organizational construction and mechanism.

\section{Acknowledgments}

This paper is the Zhejiang education and science programming research subject in 2009. The title: Researches on the Peer Education Mode of Cultivating University Students. Serial No. CS18. It is also the scientific subject of Qianjiang College of Hangzhou Normal University in 2013. The title: Researches on the Educational Function of University Dormitory. Serial No. 2013QJJW11; meanwhile, it is also the Zhejiang Philosophy and social science programming research subject, Serial No.16NDJC063YB.

\section{References}

[1] Xu Zhanlu. On Application of Peer Education Mechanism to Management of University Students. Journal of Kaifeng Institute of Education, 2009(2):54.

[2] Shi Fanghua. Review of American Schools’ Peer Psychological Counseling. Shanghai Education Research,2007(8):53.

[3] $\mathrm{Xu}$ Zhanlu. On Practice of Peer Education Mechanism in Adaptive Education of College Freshmen. Journal of Jiangxi Institute of Education, 2009(5):38.

[4] Zhang Xiaojing, Wen Shufeng and Hu Deng. Creating "Mode of Renmin University of China " of College Students’ Psychological Health Education--Integration of Liberal Education, Peer Mutual Assistance and Meticulous Service. Psychological Education, 2012(2):53. 